\title{
The Uncertain Glory of Indian Clinical Medicine: A Case for Institutional Audit of Public Tertiary Care Hospitals
}

\author{
Aveek Jayant \\ Anaesthesia and Intensive Care, Postgraduate Institute of Medical Education and Research (PGIMER), \\ Chandigarh, India
}

Medicine is a utilitarian science, which has overarching effects on the quality of human life and longevity. Its effectiveness in promoting and managing the health of people it claims to serve should be a focus of regular audit. In India, there has been a dramatic expansion of healthcare services, particularly in the private sector. On the other hand, the public health system while expanding on a smaller relative scale continues to be under stress and in some kind of perpetual duress. A large demand-supply mismatch could lie at the core of the discourse on their current state. There is, however, an added lack of efficiency as well in the delivery of these services, at least in the public perception. We suggest a compelling need for introspection and factual audit of the largest and oldest institutions that sit at the apex of public healthcare delivery. These institutions of national importance, although stellar in some aspects of their performance, have not hitherto been scrutinized in proportion to the funding they receive from the public exchequer. Regular and stringent audit in the public domain could actually propel them to higher heights and enable the realization of their potential more fully.

Amartya Sen, renowned for his empirical work on famines, has also pioneered the capabilities approach with Martha Nussbaum, both of them in turn drawing from the path-breaking work of John Rawls, the American philosopher. The capabilities approach has been applied more topically to the health sciences by the outstanding work of Sridhar Venkatapuram (Health Justice, Polity Press 2013), where the author makes a case that it is the right of all human beings to be entitled to the capacity to be healthy. In recursive mode, Sen et al. attempt to reinforce the value and inherent strengths of providing universal healthcare from a larger economic perspective. Outside of the constant lament that there is poor relative spending on health delivery of these services, a very low cost with reasonable quality is only possible if 'the society, including the political and intellectual leadership can get its act together' (Sen; Universal healthcare: the affordable dream. The Guardian January 6, 2015). A study from the Postgraduate Institute of Medical Education and Research (PGIMER), Chandigarh has reported that even as private healthcare results in catastrophic out-of-pocket expenditure and drives patients into penury, the public health delivery apparatus (although better in absolute numerical terms) does not altogether prevent impending impoverishment (Prinja et al., Ind J Med Res 2013). Outside of the costs of medicines, this study attributes the fiscal catastrophe that illness brings to a large proportion of our people to other

\section{KARGER}

E-Mail karger@karger.com

www.karger.com/aon (c) 2016 S. Karger AG, Basel

0972-7531/16/0231-0001\$39.50/0
Aveek Jayant

Associate Professor

Anaesthesia and Intensive Care, PGIMER

Chandigarh (India)

E-Mail jayant.aveek@gmail.com 
institutional factors that need to be rigorously scrutinized - the number of visits required to obtain a diagnostic test result, the time spent in hospital and whether or not there were non-standard complications such as infections, whether or not our hospitals meet a national or international curative benchmark. Each of these indexed events could be crucial to families whose earning members lose workdays in a hospital or attending a diagnostic examination or outpatient services.

It is surprising that despite not grossing substantial revenue from curative services, hospitals such as the All India Institutes of Medical Sciences (AIIMS) or the PGIMER have not been audited for clinical quality; delving further there is a brash arrogance that this is a given but in this age and time surely number crunching is the rule of the game. In a large hospital system, such as the PGIMER, there has been incessant gloating about research indices and organizing outreach days projecting the Institute but little initiative to streamline emergency systems or work toward providing the core of our constituency timelines in the form of a right to service. It is obvious that since this is not an object of regular scrutiny, there is no pressure to deliver on this count. This is in stark contrast to how easily or readily we can audit our other public systems - political executive not seen to be performing are regularly voted out, judgments of the Supreme Court are minutely scrutinized and commented upon. In a scarcely funded system, surely our science and the efficacy of its delivery need to be in the prism of the public eye.

A peculiar feature of Indian science has also been the lack of advocacy. Directors of the premier institutions in the country often sit on advisory bodies but rarely take up causes beyond their immediate position - the gall to criticize unscientific claims by public personages, the pleading for more money, innovation to reduce costs and so on. Peer review of leadership could be a gentle way to ensure that the leaders of these universities actually take up the cause of the larger common good - faculty, patients and students - the failure of leadership in fostering a proactive administration to goad powers into action to remove non-functional leaders or generate pressure to perform with more avowedly universal aims other than personal aggrandizement.
The path forward is to make local goals in each of the outreach domains of these institutions such as clinical services, education and research every year. These could easily be formulated at the departmental level starting with identifying the festering problems in each area and identifying ways in which they have to be solved within a timeframe. At the institutional level, this could take on more global outreach such as identification of funds for research, tapping industry for partnership, setting up dedicated teacher programmes, collaborating with other institutions within and outside the country and so on. Learning from larger governmental performance, the institutions can set up decentralized teams to achieve the chosen target goals. At the end of the calendar year, there could be a respectful but ruthless audit of how the aims have been achieved or reasons for failure. Leaders who professedly can neither make practical goals nor have the wherewithal to achieve them clearly will then be under pressure to relinquish leadership because what seems to hurt these institutions most is not the lack of desire to excel but the humility to accept failure. Besides it will ensure that individuals function for the avowedly larger public good rather than holding institutional machinery hostage to seeking awards or recognition.

Lastly, but not the least, bodies such as the AIIMS and PGIMER are among the most sought after institutions in medical education in the Indian sub-continent. They are mandated to deliver to the country doctors with exemplary clinical and human skills in the art and science of the practice of medicine. I have lost some of my best students to the private sector and to more welcoming institutions outside the country; we need to have students as a constituency audit to their teachers and their alma mater. There is often a frustration that this constituency has no voice and an audit of medical education has the potential to foster training that meets the demanding needs of our population. The overall holistic audit will make these institutions truly worthy of the great trust that the people and the polity repose in us; our fear to procrastinate and avoid scrutiny does us, and more importantly our entire health ecosystem, enormous harm.

The views expressed herein are personal and should not be purported to that of the Institution or its principal, the Government of India. 